\title{
Editorial
}

\section{Digital heart for life}

\author{
Yin Hua Zhang ${ }^{1,2,3, *}$ \\ ${ }^{1}$ Department of Physiology \& Biomedical Sciences, Ischemic/Hypoxic Disease Institute, Seoul National University College of Medicine, Seoul 03080, Korea, \\ ${ }^{2}$ University Hospital Research Center, Yanbian University Hospital, Yanji, Jilin Province 133000, China, ${ }^{3}$ Institute of Cardiovascular Sciences, University of \\ Manchester, Manchester M13 9PL, UK
}

Received July 26, 2019, Revised July 30, 2019, Accepted August 6, 2019

*Correspondence

Yin Hua Zhang, E-mail: yinzhang@snu.ac.kr

The 20th century witnessed a number of key breakthroughs that became cornerstones of the logic of the heart to this day starting from Einthoven's [1] development of the electrocardiogram, which is the most widely used non-invasive diagnostic tool for detecting the electrical activity, structure, and function of the heart. Following Forssmann's [2] pioneering attempt of the catheterization into the heart, performed on himself in 1929, Cournand and Richards [3,4] developed the catheterization technique on patients. Catheterization is a broadly used life-saving procedure that assesses pressure changes in the heart chambers, and other problems of the heart, especially those of coronary circulation, and is used for coronary intervention or angioplasty in cases of myocardial infarction. The next greatest innovation, by Edler and Hertz [5], is echocardiography, a non-invasive examination that made real-time "visualization" of the heart possible. Echocardiography is now an essential tool for medical diagnosis of the heart around the world. Results from these Nobel Prize-awarded innovations have significantly improved our understanding of heart diseases and their diagnosis, treatment, and prevention for over a century.

Along with these groundbreaking achievements in clinical practice, molecular reductionist approaches and the generation of high throughput data-such as those of the human genome [6], proteome [7], transcriptome [8,9], metabolomics and their interactive linkage [10] have complemented the work on the biological systems of the heart (those of cardiac electrophysiology and mechanics, such as ion channels, calcium handling, myofibril elements and signaling network properties) and the whole body. Therefore, the molecular details and genetic elements of the heart (e.g., DNAs, RNAs, proteins, miRNAs, etc.), those organize the functional regulations have almost been fully revealed. Understanding genetic and molecular networks have facilitated the identification of novel therapeutic targets for cardiac diseases. Notably, cardiac structure and their regulation are multifaceted at the transcriptional and post-transcriptional level; especially under disease circumstances, complex interactions make the biological processes extremely challenging to resolve. It has become apparent that the reductionists' approach faces limits, because it is simply impossible to incorporate such an enormous amount of information in one prototype-the functioning heart of the human body.

Computational science has made an excellent platform for the integration of DNA sequences, proteins, and interaction pathways into mathematical modelling frameworks, to assimilate each protein to a practical program to understand the complex interactions of the cell, tissues, and organ functions. This pioneering approach was initiated by Noble [11] in 1960, who began the computation of the heart with the Purkinje fibers by adapting Hodgkin-Huxley's mathematical model, another Nobel Prizewinning accomplishment [12]. The key advantage of this modelling is the integration of each element with precise mechanisms into a functioning organ, allowing quantitative analysis of the contribution and the role of individual proteins in the natural activity of the heart. From a single cell to the whole heart and human body, computer simulation has elucidated fundamental mechanisms of organ activities through cardiome and physiome projects [13-15]. Currently, numerous computer programs are available and those about the human heart are generally used for education and research in most medical areas. More importantly, due to the advantages of describing both chemical and physical machineries mathematically, detailed physiological phenomenon and pathological mechanisms can be explained and predicted at the molecular level. Computer science is a prevalent tool in clinics and is now adequate for guiding clinicians for better diagnosis, 
treatment, and prevention of heart diseases $[16,17]$.

Despite all the advances in groundbreaking technology, cardiovascular diseases remain a major cause of mortality, accounting for over 30\% mortality worldwide (World Health Organization report, 2017). The striking high numbers indicate that further research is required for better applications of these endeavors in cardiovascular medicine. It is not the lack of information or insufficient evidence are the causes of the failure; in fact, massive amounts of imaging, biometrical signals, and genomic and medical records are generated globally each year. The failure is due to the lack of an effective system which can integrate all available information of human diseases to accurately predict individualspecific settings for efficient management. Digital health maybe that system to empower human medicine.

The 20th century has also been the era of the development of artificial intelligence (AI) by Newell and Simon (another Nobel Prize-winning accomplishment) $[18,19]$. In the 21st century, AI has become a booming trend in manufacturing, agriculture, business, social services and healthcare. The core feature of AI in medical practice is to integrate and process enormous amounts of data obtained from patients and populations and analyze individual patients' information in a cost-efficient and time saving manner. Intriguingly, the decision is made through a program without knowing the mechanisms of the functioning system. Therefore, the array of data runs through a series of algorithmic operating systems of unknown mechanisms ('black box') to produce an output. Despite "black box"-uncertainty problems, AIrelated papers have frequently been published in journals such as Nature, Nature Medicine, Journal of American Cardiology College, Circulation and Circulation Research, etc. [20-30], demonstrating that $\mathrm{AI}$ and digital medicine can accurately predict the phenomena detected through conventional techniques and that they are promising tools to assist clinicians in making faster and more accurate diagnosis and treatments. AI also possesses the potential to guide patients for preventive measures. Clearly, digital health is the future direction for a positive prospect of life.

In this volume of the Korean Journal of Physiology and Pharmacology, three review articles present the current advances in the application of the "digital heart" for heart disease patients [31-33]. First, Dr. Okada's [31] laboratory from the University of Tokyo and UT-Heart Inc. in Japan demonstrated their threedimensional, multiscale, multi-physics heart simulator (UTHeart), which reproduces organ-level electrophysiology (normal 12-lead electrocardiogram) and hemodynamics of the heart with substantial improvements using finite element methods. They have demonstrated a patient-specific, multiscale heart simulation program which can predict the response to CRT and druginduced arrhythmogenic risk by reproducing the complex pathophysiology of the heart. With further validation, they suggest that this technique may be a useful tool in clinical decision-making.

Dr. Shim and their colleagues [32] from Kangwon National University and SiliconSapiens Inc., Korea, reviewed recent ad- vances in machine learning (ML) and AI and their approach of combining ML algorithms into cardiovascular physiome models of cardiac image processing, blood flow, cardiac electrical wave conduction, and cardiac toxicity analysis. Intriguingly, they have proposed a "grey" box theory, where the precise mechanisms of the physiome can complement the "black box" of AI and ML, to predict the biological processes and underlying mechanisms involved. This is an important concept and area of research to explore to improve the prospective of the digital heart and health systems.

Dr. Shin [33] from the Department of Digital Health at Sungkyunkwan University exclusively reviewed digital technology and its applications in the medical and industrial field, especially the current status and future directions of the rapidly expanding resolution of AI for benefit of humans in general. Particularly, Dr. Shin has pointed out the current hurdles of digital application systems and the development strategies in Korea, suggesting a number of important future directions for digital health in clinical practice by proposing certain key points for facilities for physicians, patients, and industries.

Taken together, the development of advanced technology is necessitated for uncovering biological functions and mechanisms for better management, especially under disease conditions. Throughout the last two centuries, digital-based computer science and their applications in medical research have played a substantial role in the understanding of human physiology and pathology, and will be an ongoing project for a wider range of biological sciences. AI and ML are new trends in cardiology and the healthcare system; whether it can efficiently integrate all the datasets from the current paradigm and significantly reduce diseaserelated morbidity and mortality needs to be validated with time, i.e., with "black box" problems unsolved, $\mathrm{AI}$ and digital medicine can never become a viable treatment option.

\section{ACKNOWLEDGEMENTS}

I would like to thank Editage (www.editage.co.kr) for English language editing.

\section{CONFLICTS OF INTEREST}

The author declares no conflicts of interest.

\section{REFERENCES}

1. Einthoven W. Un nouveau galvanomètre. In: Archives néerlandaises des sciences exactes et naturelles, série II, Vol. VI. Harlem: Soc Holl des Sciences; 1901. p.625-633.

2. Forssmann W. Die sondierung des rechten Herzens [Probing of the 
right heart]. Klin Wochenschr. 1929;8:2085-2087.

3. Cournand A, Ranges HA. Catheterization of the right auricle in man. Proc Soc Exp Biol Med. 1941;46:462-466.

4. Cournand A, Riley RL, Breed ES, Baldwin ED, Richards DW, Lester MS, Jones M. Measurement of cardiac output in man using the technique of catheterization of the right auricle or ventricle. J Clin Invest. 1945;24:106-116.

5. Edler I, Hertz CH. The use of ultrasonic reflectoscope for the continuous recording of the movements of heart walls. Kungl Fysiografiska Sällskapets i Lund Förhandlingar. 1954;24:40-58.

6. McPherson JD, Marra M, Hillier L, Waterston RH, Chinwalla A, Wallis J, Sekhon M, Wylie K, Mardis ER, Wilson RK, Fulton R, Kucaba TA, Wagner-McPherson C, Barbazuk WB, Gregory SG, Humphray SJ, French L, Evans RS, Bethel G, Whittaker A, et al; International Human Genome Mapping Consortium. A physical map of the human genome. Nature. 2001;409:934-941.

7. Anderson NL, Anderson NG. Proteome and proteomics: new technologies, new concepts, and new words. Electrophoresis. 1998; 19:1853-1861.

8. Schena M, Shalon D, Davis RW, Brown PO. Quantitative monitoring of gene expression patterns with a complementary DNA microarray. Science. 1995;270:467-470.

9. Brenner S, Johnson M, Bridgham J, Golda G, Lloyd DH, Johnson D, Luo S, McCurdy S, Foy M, Ewan M, Roth R, George D, Eletr S, Albrecht G, Vermaas E, Williams SR, Moon K, Burcham T, Pallas M, DuBridge RB, et al. Gene expression analysis by massively parallel signature sequencing (MPSS) on microbead arrays. Nat Biotechnol. 2000;18:630-634.

10. Nicholson JK, Lindon JC. Systems biology: metabonomics. Nature. 2008;455:1054-1056.

11. Noble D. Cardiac action and pacemaker potentials based on the Hodgkin-Huxley equations. Nature. 1960;188:495-497.

12. Hodgkin AL, Huxley AF. A quantitative description of membrane current and its application to conduction and excitation in nerve. $J$ Physiol. 1952;117:500-544.

13. Noble D. The rise of computational biology. Nat Rev Mol Cell Biol. 2002;3:459-463.

14. Kitano H. Computational systems biology. Nature. 2002;420:206210.

15. Hunter PJ, Borg TK. Integration from proteins to organs: the Physiome Project. Nat Rev Mol Cell Biol. 2003;4:237-243.

16. Lee KE, Kim KT, Lee JH, Jung S, Kim JH, Shim EB. Computational analysis of the electromechanical performance of mitral valve cerclage annuloplasty using a patient-specific ventricular model. Korean J Physiol Pharmacol. 2019;23:63-70.

17. Okada JI, Yoshinaga T, Kurokawa J, Washio T, Furukawa T, Sawada K, Sugiura S, Hisada T. Arrhythmic hazard map for a 3D wholeventricle model under multiple ion channel block. Br J Pharmacol.
2018;175:3435-3452.

18. Newell A, Simon H. The logic theory machine--a complex information processing system. IRE Trans Inf Theory. 1956;2:61-79.

19. Fogel AL, Kvedar JC. Artificial intelligence powers digital medicine. NPJ Digit Med. 2018;1:5.

20. Topol EJ. High-performance medicine: the convergence of human and artificial intelligence. Nat Med. 2019;25:44-56.

21. He J, Baxter SL, Xu J, Xu J, Zhou X, Zhang K. The practical implementation of artificial intelligence technologies in medicine. Nat Med. 2019;25:30-36.

22. Hannun AY, Rajpurkar P, Haghpanahi M, Tison GH, Bourn C, Turakhia MP, Ng AY. Cardiologist-level arrhythmia detection and classification in ambulatory electrocardiograms using a deep neural network. Nat Med. 2019;25:65-69.

23. Attia ZI, Kapa S, Lopez-Jimenez F, McKie PM, Ladewig DJ, Satam G, Pellikka PA, Enriquez-Sarano M, Noseworthy PA, Munger TM, Asirvatham SJ, Scott CG, Carter RE, Friedman PA. Screening for cardiac contractile dysfunction using an artificial intelligenceenabled electrocardiogram. Nat Med. 2019;25:70-74.

24. Mincholé A, Rodriguez B. Artificial intelligence for the electrocardiogram. Nat Med. 2019;25:22-23.

25. Tsay D, Patterson C. From machine learning to artificial intelligence applications in cardiac care. Circulation. 2018;138:2569-2575.

26. Krittanawong C, Zhang H, Wang Z, Aydar M, Kitai T. Artificial intelligence in precision cardiovascular medicine. J Am Coll Cardiol. 2017;69:2657-2664.

27. Dey D, Slomka PJ, Leeson P, Comaniciu D, Shrestha S, Sengupta PP, Marwick TH. Artificial intelligence in cardiovascular imaging: JACC state-of-the-art review. J Am Coll Cardiol. 2019;73:1317-1335.

28. Weintraub WS, Fahed AC, Rumsfeld JS. Translational medicine in the era of big data and machine learning. Circ Res. 2018;123:12021204.

29. Rodriguez F, Scheinker D, Harrington RA. Promise and perils of big data and artificial intelligence in clinical medicine and biomedical research. Circ Res. 2018;123:1282-1284.

30. Ambale-Venkatesh B, Yang X, Wu CO, Liu K, Hundley WG, McClelland R, Gomes AS, Folsom AR, Shea S, Guallar E, Bluemke DA, Lima JAC. Cardiovascular event prediction by machine learning: the multi-ethnic study of atherosclerosis. Circ Res. 2017;121:10921101.

31. Okada J, Washio T, Sugiura S, Hisada T. Clinical and pharmacological application of multiscale multiphysics heart simulator, UTHeart. Korean J Physiol Pharmacol. 2019;23:295-303.

32. Hwang M, Leem CH, Shim EB. Toward a grey box approach for cardiovascular physiome. Korean J Physiol Pharmacol. 2019;23:305310.

33. Shin SY. Current status and future direction of digital health in Korea. Korean J Physiol Pharmacol. 2019;23:311-315. 